\title{
EVALUATING CUSTOMER SATISFACTION BY USING FUZZY ANALYTICAL HIERARCHY PROCESS FOR BANKING SERVICES
}

\author{
Dr. Elsayed A. Elsayed \\ Department of Industrial Engineering, \\ Zagazig University, Egypt
}

\begin{abstract}
Customer satisfaction is important because it provides marketers and business owners with a metric that they can use to manage and improve their businesses, where companies need to fight for their survival, rendered evident that building and managing relationships with customers is vital. In the service area the construct of satisfaction is bound to the interaction with the service provider, conferring to the evaluation even greater importance. This paper offers an approach to Customer satisfaction measurement in the banking services by FAHP. Fuzzy AHP is a highly complex methodology and requires more numerical calculations in assessing composite priorities than the traditional AHP and hence it increases the effort.

The findings of the study supported the contention that the Professional knowledge (F1), Waiting time (F3), Service quality and demand (T1), Customer kind (S1), Education (S3) are core criteria in customer satisfaction respectively are the most factors for customer satisfaction. However, customer satisfaction alone cannot achieve the objective of creating a loyal customer base. Some researchers also argued, that customer satisfaction and loyalty are not directly correlated, particularly in competitive business environments because there is a big difference between satisfaction, which is a passive customer condition and loyalty, which is an active or proactive relationship with the organization.
\end{abstract}

Key words: Banking Services, Customer Relationship Management, Customers Satisfaction, Relationship Marketing.

Cite this Article: Elsayed A. Elsayed, Evaluating Customer Satisfaction by Using Fuzzy Analytical Hierarchy Process for Banking Services, International Journal of Industrial Engineering Research and Development, 8(1), 2017, pp. 27-48.

https://iaeme.com/Home/issue/IJIERD?Volume $=8 \&$ Issue $=1$

\section{INTRODUCTION}

Customers are the source of business profits; hence, satisfying customer needs is the objective pursued by companies. According to Hansemark and Albinson satisfaction is an overall customer attitude towards a service provider, or an emotional reaction to the difference between what customers anticipate and what they receive, regarding the fulfillment of some 
needs, goals or desire“. Customer loyalty on the other hand refers to a deeply held commitment to re-buy a preferred product or service in the future despite situational influences and marketing efforts having the potential to cause switching behavior.

There are many factors that affect customer satisfaction. Such factors include friendly employees, courteous employees, knowledgeable employees, helpful employees, accuracy of billing, billing timeliness, competitive pricing, service quality, good value, billing clarity and quick service (Hokanson, 1995).

Customer satisfaction is the heart of marketing. The ability of an organization to satisfy customers is vital for a number of reasons. For example, it has been shown that dissatisfied customers tend to complain to the company and in some cases seek redress from them more often to relieve cognitive dissonance and bad consumption experiences. If service providers fail to properly address such behavior, it can have serious adverse effect. In extreme cases of dissatisfaction, customers may resort to negative word-of-mouth as a means of getting back to the company. The unsatisfied customers may choose not to defect, because they do not expect to receive better service elsewhere or if the switching cost is high. Additionally, satisfied customers may seek for competitors because they believe they might receive better service elsewhere.

There are six reasons why customer satisfaction is so important:

- It's a leading indicator of consumer repurchase intentions and loyalty

- It's a point of differentiation

- It reduces customer churn

- It increases customer lifetime value

- It reduces negative word of mouth

- It's cheaper to retain customers than acquire new ones

Companies try to maintain their loyalty with their customers by improving product and service quality. As a result in the last decade, many national indices have been developed in order to measure consumer satisfaction across a wide range of organizations. Thus, at the national level, the customer satisfaction index (CSI) is used to measure companies and organizations how they satisfy customers' needs. The CSI's model can be also used for comparing services and products within an industry. Most countries have set their own customer satisfaction indices to measure customer satisfaction and the business performance of companies and organizations. The first truly national customer satisfaction index was the Swedish Customer Satisfaction Barometer SCSB developed in 1989. The SCSB includes 31 major Swedish industries. The original Swedish Barometer used perceived value and a single measure of customer expectations (Fornell, 1992).

The list of bank service attributes used for the measurement of satisfaction comprises elements like: appearance of the facility, attitude and behavior of staff, decor and atmosphere, business hours, interest rate, waiting time. Bank customers may regard some of these elements as being not equally important as the others.

Decision makers understood that distanced judgment is more persuasive than fixed value judgments. The reason is the individual often cannot explicitly express his preferences regarding the fuzzy nature of comparison process. Since the relative importance specified by the AHP decision makers is oral, it is vague and imprecise. Decision makers often prefer to employ oral presentation rather than numerical value. Because of the nature of pair comparisons they cannot explicitly express their opinions about priorities correctly. In such circumstances the useful solution is to make decisions on the basis of multiple conditions and goals to achieve a relatively desirable level of achievement. These issues have caused the 
nature of decision making to be involved with complexities and ambiguities in most minor and most major cases. Consequently, most decisions are made in a fuzzy environment.

Therefore, considering that the fuzzy logic method is applied for decision making in uncertain and ambiguous situations, using this method can decrease ambiguities and increase the effectiveness of decisions made.

\section{FUZZY ANALYTIC HIERARCHY PROCESS (FAHP)}

Analysis Hierarchical Process (AHP) is a multi-criteria decision making tool that was proposed by Saaty on 1980. Since it was introduced, AHP have been one of the most useful multi-criteria decision making tools available to decision makers and researchers. The conventional AHP is unable to veritably reflect the way human thinks and judges. AHP is criticized for using lopsided judgmental scales and its inability to properly consider the inherent uncertainty and carelessness of pair comparisons. To overcome these shortcomings, fuzzy AHP is developed to resolve the expanded hierarchical problems.

Decision makers understood that distanced judgment is more persuasive than fixed value judgments. The reason is the individual often cannot explicitly express his preferences regarding the fuzzy nature of comparison process. Since the relative importance specified by the AHP decision makers is oral, it is vague and imprecise. Decision makers often prefer to employ oral presentation rather than numerical value. Because of the nature of pair comparisons they cannot explicitly express their opinions about priorities correctly. In such circumstances the useful solution is to make decisions on the basis of multiple conditions and goals to achieve a relatively desirable level of achievement. AHP have been one of the most useful multi-criteria decision making tools available to decision makers and researchers. Therefore, considering that the fuzzy logic method is applied for decision making in uncertain and ambiguous situations, using this method can decrease ambiguities and increase the effectiveness of decisions made [2009].

\subsection{Definitions}

Fuzzy logic is an extension of classical Boolean logic that is able to use the concept of partial truth. Standard Boolean logic supports only two values: 0 (false) and 1 (true), while fuzzy logic supports a range of values from a complete lie to the complete truth covering the whole range of values from 0 to 1 . In classic set theory for each element is strictly determined if it belongs or does not belongs to a particular set. Fuzzy set is an extension of the classic set. With fuzzy sets one element may partially belong to the set. Fuzzy number is a generalization of real numbers. It is specified with interval of real numbers between 0 and 1 . It is possible to use different fuzzy numbers according to the situation, but in practice trapezoidal and triangular fuzzy numbers are most used.

Fuzzy Set Theory: Fuzzy set theory was first developed in 1965, when L.A. Zadeh was trying to solve fuzzy phenomenon problems that exist in the real world, such as uncertain, incomplete, unspecific and fuzzy situations. Fuzzy set theory has more advantages in describing set concepts in human language than traditional set theory. It demonstrates the unspecific and fuzzy characteristics of language through evaluation and uses a membership function concept to represent the field in which a fuzzy set can permit situations such as incompletely belonging to and incompletely not belonging to.

In contrast to classical set theory for coping with Boolean logic problems, fuzzy sets were proposed to represent the degree of elements belonging to the specific sets. Instead of using the characteristic function as a mapping function, a fuzzy subset $\tilde{A}$ of a universal set $X$ can be defined by its membership function $\mu_{\tilde{A}}(X)$. 
If uncertainty (fuzziness) of human decision-making is not taken into account, the results can be misleading. A commonality among terms of expression, such as "very likely", " "probably so", "not very clear", "rather dangerous" that are often heard in daily life, is that they all contain some degree of uncertainty (Tsaur, Tzeng, \& Wang, 1997; Tsaur, Chang, \& Yen, 2002). Fuzzy theory thus is used to solve such kind of problems, and it has been applied in a variety of fields in the last four decades.

Theory of fuzzy sets has evolved in various directions, and two distinct directions are: treating fuzzy sets as precisely defined mathematical objects subject to the rules of classical logic, and the linguistic approach. The underlying logic of linguistic approach is that the truthvalues are fuzzy sets and the rules of inference are approximate rather than exact (Gupta, Saridis, \& Gaines, 1977). A triangular fuzzy number, a special case of a trapezoidal fuzzy number, is very popular in fuzzy applications.

Fuzzy Number: We order the Universe of discourse such that $U$ is a whole target that we discuss, and each target in the Universe of discourse is called an element. We have fuzzy $\tilde{A}$, which on $U$ states that random $X \rightarrow U$ appointing a real number $\mu_{\tilde{A}}(x) \rightarrow[0,1]$. We call anything above that level of $X$ under $A$. The universe of real number $R$ is a triangular fuzzy number (TFN): $\tilde{A}$, which means $X \in R$, appointing $\mu_{\tilde{A}}(x) \in[0,1]$,

$$
\mu_{\tilde{A}}(X)=\left\{\begin{array}{cc}
\frac{X-L}{M-L} & L \leq X \leq M \\
\frac{U-X}{U-M} & M \leq X \leq U \\
0 & \text { otherwise }
\end{array}\right\}
$$

The triangular fuzzy number above can be shown as $\tilde{A}=(L ; M ; U)$, where $L$ and $U$ represent fuzzy probabilities between the lower and upper boundaries of evaluation information, as shown in Figure 1.

Assume two fuzzy numbers, $\tilde{A}_{1}=(L 1 ; M 1 ; U 1)$, and $\widetilde{A_{2}}=(L 2 ; M 2 ; U 2)$; then

$$
\tilde{A}_{1} \oplus \tilde{A}_{2}=(L 1, M 1, U 1) \oplus(L 2, M 2, U 2)=(L 1+L 2, M 1+M 2, U 1+U 2)
$$

where

$$
L_{i}>0, M_{i}>0, U_{i}>0
$$

$$
\tilde{A}_{1} \otimes \tilde{A}_{2}=(L 1, M 1, U 1) \otimes(L 2, M 2, U 2)=(L 1 L 2, M 1 M 2, U 1 U 2)
$$

where

$$
\begin{aligned}
& L_{i}>0, M_{i}>0, U_{i}>0 \\
& \tilde{A}_{1} \ominus \tilde{A}_{2}=(L 1, M 1, U 1) \ominus(L 2, M 2, U 2)=(L 1-L 2, M 1-M 2, U 1-U 2)
\end{aligned}
$$

where

$$
\begin{aligned}
& L_{i}>0, M_{i}>0, U_{i}>0 \\
& \tilde{A}_{1} \div \tilde{A}_{2}=(L 1, M 1, U 1) \div(L 2, M 2, U 2)=(L 1 / L 2, M 1 / M 2, U 1 / U 2)
\end{aligned}
$$

where where

$$
L_{i}>0, M_{i}>0, U_{i}>0
$$

$$
\left((A)_{-}^{\sim} 1\right)^{-1}=(L 1, M 1, U 1)^{-1}=(1 / L 1,1 / M 1,1 / U 1),
$$

$$
L_{i}>0, M_{i}>0, U_{i}>0
$$


Other forms of the membership function can be easily employed by using the same procedures.

$\mu_{\tilde{A}}(x)$

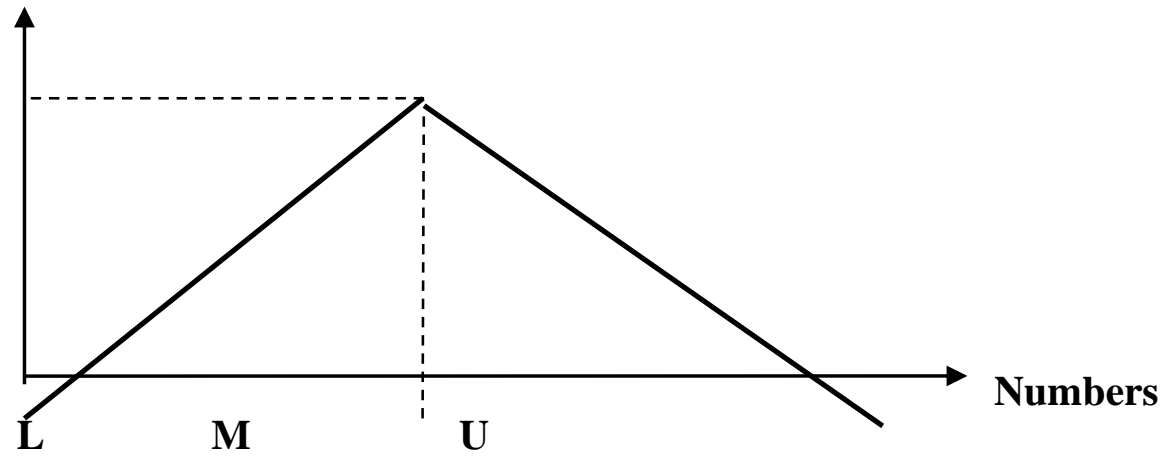

Figure 1Triangular Fuzzy Number (Membership Function)

$\mu_{\tilde{A}}(x)$

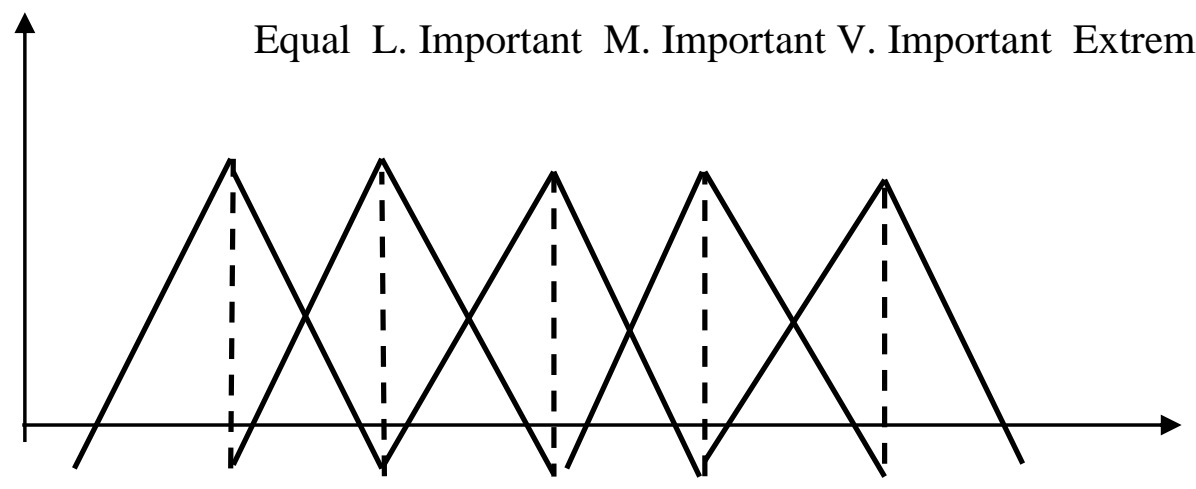

$\begin{array}{llllllll}1 / 2 & 1 & 3 / 2 & 2 & 5 / 2 & 3 & 7 / 2 & \mathrm{Ri}\end{array}$

Figure 2 Fuzzy system of quintuple criterion due to convert qualitative criterions to quantitative criterions.

Table 1 Fuzzy Membership Function for Linguistic Values [59]

\begin{tabular}{|c|c|}
\hline Linguistic variable & Triangular fuzzy number \\
\hline Absolutely Higher important (A.H) & $(5 / 2,3,7 / 2)$ \\
\hline Much Higher important (V.H) & $(2,5 / 2,3)$ \\
\hline Higher important (H) & $(3 / 2,2,5 / 2)$ \\
\hline Relatively higher important(R.H) & $(1,3 / 2,2)$ \\
\hline Moderately important (M) & $(1 / 2,1,3 / 2)$ \\
\hline Equal important(E) & $(1,1,1)$ \\
\hline
\end{tabular}

Fuzzy Logic: is a form of multi-valued logic derived from fuzzy set theory to deal with reasoning that is approximate rather than precise. In contrast with "crisp logic", where binary sets have binary logic, fuzzy logic variables may have a truth value that ranges between 0 and 1 and is not constrained to the two truth values of classic propositional logic [1985] Furthermore, when linguistic variables are used, these degrees may be managed by specific functions. Fuzzy logic emerged as a consequence of the 1965 proposal of fuzzy set theory by Lotfi Zadeh [1965], and Adekoya [2010] though fuzzy logic has been applied to many fields, from control theory to artificial intelligence, it still remains controversial among most 
statisticians, who prefer Bayesian logic, and some control engineers, who prefer traditional two-valued logic.

Fuzzy linguistic variable: The fuzzy linguistic variable is a variable that reflects the different levels of human language. Its value represents the range from natural to artificial language. When one precisely reflects the value or meaning of a linguistic variable, there must be an appropriate way to change. Variables for a human word or sentence can be divided into numerous linguistic criteria, such as equally important, moderately important, strongly important, very strongly important, and extremely important. (See Figure2), (see Table1).

Decision makers understood that distanced judgment is more persuasive than fixed value judgments. The reason is the individual often cannot explicitly express his preferences regarding the fuzzy nature of comparison process. Since the relative importance specified by the AHP decision makers is oral, it is vague and imprecise. Decision makers often prefer to employ oral presentation rather than numerical value. Because of the nature of pair comparisons they cannot explicitly express their opinions about priorities correctly. In such circumstances the useful solution is to make decisions on the basis of multiple conditions and goals to achieve a relatively desirable level of achievement. These issues have caused the nature of decision making to be involved with complexities and ambiguities in most minor and most major cases. Consequently, most decisions are made in a fuzzy environment.

The primary reason for using triangular fuzzy numbers can be stated as their intuitive and computational-efficient representation. A linguistic variable is defined as a variable whose values are not numbers, but words or sentences in natural or artificial language. The concept of a linguistic variable appears as a useful means for providing approximate characterization of phenomena that are too complex or ill-defined to be described in conventional quantitative terms.

\subsection{Calculation of Fuzzy AHP}

1. Comparing the performance score, Comparison matrix: Based on the input of the questionnaire information, fuzzy positive matrices are formed.

2. Construct fuzzy comparison matrix

3. Construct fuzzy positive matrices. The scores of pairwise comparison are transformed into linguistic variables, which are represented by positive triangular fuzzy numbers listed in Table 3.

4. Analyze consistency. The priority of the elements can be compared by the computation of eigenvalues and eigenvectors:

$$
\begin{gathered}
A . W=\lambda_{\max } \cdot W \\
(\tilde{A} i), \text { where }(A-\lambda I) W=0
\end{gathered}
$$

Where $\mathrm{w}$ is the eigenvector, the weight vector, of matrix $\mathrm{A}$, and $\lambda_{\max }$ is the largest eigenvalue of $\mathrm{A}$. The consistency property of the matrix is then checked to ensure the consistency of judgments in the pairwise comparison. The consistency index (CI) and consistency ratio (CR) are defined as (Saaty, 1980):

Therefore, the matrix $A$ should be tested for consistency using index, $C I$, which has been constructed.

$$
C I=\left(\lambda_{\max }-n\right) /(n-1)
$$

CI estimates the level of consistency with respect to a comparison matrix. Then, because $C I$ is dependent on $n$, a consistency ratio $C R$ is calculated, which is dependent of $n$ as shown below. 
Where $\mathrm{CI}$ is the consistency index, $R I$ is random index (RI) generated for a random matrix of order $n$, and CR is the consistency ratio (Saaty, 1993). The general rule is that CR $\leq 0.1$ should be maintained for the matrix to be consistent. Otherwise, all or some comparisons must be repeated in order to resolve the inconsistencies of the pair-wise comparisons.

Table 2 The R.I. for Different Size Matrices

\begin{tabular}{|c|c|c|c|c|c|c|c|c|}
\hline Numbers & 3 & 4 & 5 & 6 & 7 & 8 & 9 & 10 \\
\hline R.I. & 0.52 & 0.89 & 1.11 & 1.25 & 1.35 & 1.40 & 1.45 & 1.49 \\
\hline
\end{tabular}

1. Calculate fuzzy weights $\widetilde{W}$

2. Defuzzyfication

The defuzzification methods were defined empirically, evaluating mainly the concept of continuity and discontinuity in fuzzification. It is the process of transforming the fuzzy numbers and linguistic values in a standard numeric value (crisp variable). The fuzzy set is usually the union of several subsets representing the conclusion of a fuzzy proposition. Normally, a fuzzy set cannot be represented by a singleton; therefore defuzzification can only be undertaken with the loss of information.

There are several ways of finding a representative number. Two common ways are Centroid method, and weighted abscissa method. The centroid technique finds the point where a vertical line would slice the aggregate set into two equal masses.

The study finds the best crisp value, or non-fuzzy value, in accordance with the Centroid method (CO). The concept means that we calculate clear weights for each index (a crisp solution). The calculation method is as follows:

$$
B N P_{i}=\frac{(U i-L i)+(M i-L i)}{3}+L i \quad, \forall_{i}
$$

\section{LITERATURE REVIEW}

Thomas L. Saaty, illustrates an introduction to the Analytic Hierarchy Process. The principles and the philosophy of the theory are summarized giving general background information of the type of measurement utilized, its properties and applications.

Evangelos Triantaphyllou, and Stuart H. Mann, examined some of the practical and computational issues involved when the AHP method is used in engineering applications.

Jan Jantzen, defines a logic based on the two truth values true and false is sometimes inadequate when describing human reasoning. Fuzzy logic uses the whole interval between 0 (false) and 1 (true) to describe human reasoning. As a result, fuzzy logic is being applied in rule based automatic controllers, and this paper is part of a course for control engineers.

M. Bevilacqua, and M. Braglia, describes an application of the Analytic Hierarchy Process (AHP) for selecting the best maintenance strategy for an important Italian oil refinery (an Integrated Gasification and Combined Cycle plant). Five possible alternatives are considered: preventive, predictive, condition-based, corrective and opportunistic maintenance. The best maintenance policy must be selected for each facility of the plant (about 200 in total). The machines are clustered in three homogeneous groups after a criticality analysis based on internal procedures of the oil refinery. With AHP technique, several aspects, which characterize each of the above-mentioned maintenance strategies, are arranged in a hierarchic structure and evaluated using only a series of pairwise judgments.

Ling $\mathrm{Xu}$, and Jian-Bo Yang, defines the main features of multiple criteria decision making (MCDM) problems are first summarized followed by a list of typical techniques used in 
MCDM analysis. To tackle the main features of MCDM problems, the Evidential Reasoning (ER) approach, a recent development and a breakthrough in handling hybrid MCDM problems with uncertainties, is introduced. Then the Intelligent Decision System, a software developed to implement the ER approach, is briefly demonstrated with an example followed by a comparison between the ER approach and the AHP method, one of the most widely used MCDM methods. Finally some terminologies related to the ER approach and the IDS software are defined and relevant references are listed.

Thomas L. Saaty, illustrates several examples that serve to validate the AHP/ANP with matrices hierarchies and networks. They are then followed by a discussion of the real numbers and how they are generated without the need for an absolute zero, and how they define an absolute scale of measurement that also does not need an absolute zero. In the AHP/ANP the measurement of an alternative depends on what other alternatives it is compared with. The result is that rank can change if alternatives are added or deleted, something that does not occur in one-at-a-time rating of the alternatives by comparing them with an ideal. An example is provided to show that this is natural and need not involve new criteria or change in judgments. A brief discussion of Utility Theory, the other multi-criteria theory, which uses interval scales to measure intangibles and some of its problems and paradoxes, is given.

Ali Kamil Taslicali, Sami Ercan, identifies the critical benefits and factors of decision making models in a changing technological environment. They clearing that decision making models are helping tools for the managers or decision makers to make future plans by using qualitative or quantitative data. In this research; a general idea about decision making models and, comparison between the two important models, Analytical Hierarchy Process (AHP) and Analytical Network Process (ANP), are introduced.

Hung-Ping Wang, Yao-Min Fang, and Tien-Yin Chou, defined the special environment condition and the development of environmentally sensitive areas in Taiwan, when the typhoons bring the heavy rain, debris flow occurred frequently at the mountain areas and caused serious disasters. Debris flow potential assessment is a many influencing factors, the fuzzy situation of uncertainty and quantitative assessment problem. In this study, cooperating AHP method and Fuzzy Theory as a method of Multi Criteria Decision Making, infer the relation and weight among each assessment parameter. Finally, by using the case of Chen-YuLan Steam and Kalmaegi typhoon as the practical application case, and the assessment results indicate that in this assessment model it has a good forecast effect before typhoons coming.

Thomas L. Saaty, illustrates decisions involve many intangibles that need to be traded off. To do that, they have to be measured a long side tangibles whose measurements must also be evaluated as to, how well, they serve the objectives of the decision maker. The Analytic Hierarchy Process (AHP) is a theory of measurement through pairwise comparisons and relies on the judgments of experts to derive priority scales. It is these scales that measure intangibles in relative terms. The comparisons are made using a scale of absolute judgments that represents how much more; one element dominates another with respect to a given attribute. The judgments may be inconsistent, and how to measure inconsistency and improve the judgments, when possible to obtain better consistency is a concern of the AHP. The derived priority scales are synthesized by multiplying them by the priority of their parent nodes and adding for all such nodes. An illustration is included.

Irfan Syamsuddin, and Junseok Hwang, proposes the application of Analytic Hierarchy Process (AHP) methodology to guide decision makers in banking industries to deal with information security policy. The model is structured according aspects of information security policy in conjunction with information security elements. We found that cultural aspect is valued on the top priority among other security aspects, while confidentiality is considered as the most important factor in terms of information security elements. 
Chiang Ku Fan, and Shu Wen Cheng, illustrates a curriculum performance evaluation method combining the Analytical Hierarchy Process (AHP) and the Technique for Order Preference by Similarity to Ideal Solution (TOPSIS). The AHP is used in obtaining the relative weights of criteria, and then the TOPSIS approach is employed to rank how universities perform in using this curriculum. Research results find that experts select the most appropriate curricula in universities for life insurance companies based on the following rankings: personal insurance, insurance company operations and management, and insurance theory and legal. The results suggest that Shih Chien University (SCU) provides the most appropriate curriculum and its students are the most employable graduates by life insurance companies in Taiwan. The proposed AHP-based algorithm significantly helps faculty in departments of risk management and insurance to improve their curriculum design. The proposed algorithm, which is objective and systematic in selection procedures, can help human resources managers recruit highly qualified graduates for their companies.

Serkan Ball and Serdar Korukoğlu, developed a fuzzy decision model to select appropriate operating system for computer systems of the firms by taking subjective judgments of decision makers into consideration. Proposed approach is based on Fuzzy Analytic Hierarchy Process (FAHP) and TOPSIS (Technique for Order Preference by Similarity to Ideal Solution) methods. FAHP method is used in determining the weights of the criteria by decision makers and then rankings of the operating systems are determined by TOPSIS method. Empirical study has also been demonstrated.

ADEKOYA, A., G. et al., employed Analytic Hierarchy Process (AHP) as an evaluative tool for strategic reconsolidation of capital base by banks, using the recent experience of six merger/ acquisition mega banks.

Dejan Čehulić et al., show how to use a multi-criteria decision making method called the Analytic Hierarchy Process (AHP) to compare a bank's financial ratios. Within this study, the AHP model for the comparison of a bank's financial ratios was developed and validated. The application for comparing bank's financial ratios has been developed using Microsoft Office Excel and Visual Basic programming language. It enables comparison of financial ratios of up to 15 banks, using a developed AHP model and providing objective's (criteria and subcriteria) relative significance and priorities of the alternatives (banks) as a result of the comparison. In the paper a developed application is used to compare 15 largest banks in Croatia according to the total value of assets as of 30thth June 2009.

Ali GÖRENER, proposed to enhance Strengths, Weaknesses, Opportunities and Threats SWOT analysis with multi-criteria decision making techniques called Analytic Hierarchy Process (AHP) and Analytic Network Process (ANP). AHP approach achieves pairwise comparisons among factors or criteria in order to prioritize them at each level of the hierarchy using the eigenvalue calculation. In addition to AHP, ANP technique is a general form that allows interdependencies, outer dependencies and feedbacks among decision elements in the hierarchical or nonhierarchical structures. The main purpose of this paper is to explain how to use the AHP and ANP methods for prioritize of SWOT factors and compare them.

S.A. Nabavi Chashmi et al., evaluates and ranks the performance of Mellat Bank branches under the supervision of Sari area based on financial challenges after privatization using AHP FUZZY \& TOPSIS techniques. In this study, in order to achieve the goal, 6 cases of financial challenges and 25 cases of indices related to these challenges which are measurable at branches under the supervision of Sari area have been analyzed and studied. Based on this, in addition to a thorough review of subject literature related to performance evaluation, privatization and establishing the financial challenges after privatization , 26 experts and professionals of Mellat Bank branches in this town (Sari) have answered the questionnaires which have been ranked by collecting the necessary data and information using library study 
and field study and the final weight of the related indices to financial challenges has been calculated by AHP FUZZY software and the indices have been prioritized based on that. Then by using TOPSIS software, ranking of 13 branches under the supervision of this town (Sari) based on the after mentioned challenges has been dealt bean. The study result indicated that concerning the calculated final weights, the indices of active issued cards number (withdrawal $\&$ credit), the percentage of cash machine (A.T.M) functioning time and the percentage growth and balance of the other Rial resources have stood first to third in priority and in ranking of this town branches, in addition to considering all financial challenges and indices related to Farhang, Enghelab and Khadamate Darmani in Sari have stood first to third.

Salem Yousef Al Wahaidi, illustrates in the prequalification process, the clients save the time, efforts by selecting competent contractors to implement their projects upon their requirements as well as protecting contractors from being awarded work they are incapable of doing it. Most of the implementing agencies in Gaza Strip depend on the Palestinian Contractors Union (PCU) classification and consider it as a prequalification process. The study also investigate the existing prequalification practices in Gaza Strip, setting prequalification criteria, applying the Analytical Hierarchy Process (AHP) to determine its weights, conducting case study by AHP, and developing computerized software based on AHP. The results showed the high importance of the adopted prequalification criteria of the contractors. Based on AHP, it was found that the financial stability of the company is the most important criterion with respect to its weight. Moreover, technical ability, past performance, management capability, experience and reputation of the company has considerable weights.

\section{CASE STUDY}

The objective of this paper was to determine the satisfaction level of the customers of a specific Kingdom Of Saudi Arabia bank. The survey represents a qualitative research and was based on a questionnaire. Consequently primary data was collected. Responses were gathered from 100 retail clients (investors) of Saudi Arabia banks. The response clients were interviewed, face to face, on their way out of the bank. Their age ranges between 30 and 60 years.

Based on the multidimensional satisfaction construct and literature on the subject, a list of attributes was compiled:

\section{Technical quality $(\mathrm{T})$}

- Service quality and demand (T1)

- Service quality perception (T2)

- The ideal public service (T3)

- Global quality of services (T4)

- Reception and welcome (T5)

- Services area (T6)

- Services identification (T7)

2. Functional quality (F)

- Professional knowledge (F1)

- Information clarity (F2)

- Waiting time (F3)

- Attention and professional interest (F4)

- Professional reliability (F5) 
3. Corporate image $(\mathrm{C})$

- Modernity (C1)

- The orientation to the customer $(\mathrm{C} 2)$

- The spreading of the services (C3)

4. Socio-demographic (S)

- Customer kind (S1)

- Gender (S2)

- Education (S3)

In order to have grounds for comparison the customers were also asked to rank their overall satisfaction with the bank. They also stated their average waiting time and how often they usually use banking services. The most important element in the performed analysis refers to the customer satisfaction, followed by the changes in evaluating banking system. The algorithm in this case is based on the concept of fuzzy set theory and the analysis hierarchical process. This case constructs linguistic values to the subjective judgments and analyzes the ranking results of the customer satisfaction measurement with respect to specific banks. Thus, the study demonstrates a successful way of satisfaction measurement in SAUDI ARABIA banks.

\subsection{Methodology}

In this case we present a AHP-FUZZY methodology for satisfaction measurement costumers in SAUDI ARABIA banks. There are many uncertainties, vagueness's, and imprecisions in the real world when dealing with decisions of multiple criteria. Fuzzy set theory treats a kind of uncertainty called fuzziness. It shows that the boundary of "yes" or "no" is ambiguous and appears in the meaning of words or included in the subjunctives or recognition of human beings.

AHP have been one of the most useful multi-criteria decision making tools available to decision makers and researchers. Although AHP is sophisticated in recording knowledge, the conventional AHP is unable to veritably reflect the way human thinks and judges [26]. Although it uses a precise yardstick to compare the opinions of decision makers, the conventional AHP becomes confusing. AHP is criticized for using lopsided judgmental scales and its inability to properly consider the inherent uncertainty and carelessness of pair comparisons. To overcome these shortcomings, fuzzy AHP is developed to resolve the expanded hierarchical problems.

The methodology can accommodate Fuzzy system of quintuple criterion due to convert qualitative criterions to quantitative criterions. It employs fuzzy numbers and linguistic variables to model the satisfaction on the measurement criteria, sub-criteria and the judgment of the decision makers with respect to these criteria and sub-criteria.

\subsection{Calculation Steps}

The detailed descriptions of the major steps are given in the following:

\section{Step 1: Defining fuzzy decision matrix}

Investors are selected as the decision makers for assessing satisfaction banks. The criteria weightings are assessed by decision makers in linguistic language. The ratings of indexes are formulated based on analyzing the banks tendering documents and decision makers' judgment. 


\section{Step 2: Formulating the complex fuzzy decision matrix}

The fuzzy decision matrix and the fuzzy attribute weightings are formulated by converting the linguistic terms into triangular fuzzy numbers according to Table 1 and can be transformed into complex decision matrix.

\section{Step 3: Normalizing the complex fuzzy decision matrix}

The first part of paired comparisons matrixes according to the model presented in table (4.2) refers to the dimensional paired comparisons matrix.

\section{Step 4: Calculating satisfaction indices score}

Next part refers to paired comparisons matrix employed for each index of dimensions. To prioritize Customer Satisfaction a critical question came up: Which dimension should be given higher priority:

1. Pairwise the main criteria

In order to do paired comparisons based on 4 said dimensions 6 paired comparisons were made. The related question is that to: "what extent Technical Quality dimension is important as compared with functional quality?" Normalized weights column at the end of table shows the results of comparisons done through Fuzzy approach. Table 2 illustrates the summary of 100 questioners for main dimension.

Table 2 Summary of 100 Questioners for Main Dimensions

\begin{tabular}{|c|c|c|c|c|c|c|}
\hline \multirow[b]{2}{*}{ Dimension } & \multicolumn{5}{|c|}{ Importance } & \multirow{3}{*}{ Weights } \\
\hline & Not & Weak & Important & V. Important & $\begin{array}{l}\text { Extremely } \\
\text { Important }\end{array}$ & \\
\hline Weights & 1 & 2 & 3 & 4 & 5 & \\
\hline \# of Voters T & 4 & 12 & 18 & 30 & 36 & 3.82 \\
\hline$\#$ of Voters F & 8 & 14 & 10 & 38 & 30 & 3.68 \\
\hline \# of Voters S & 10 & 18 & 40 & 12 & 20 & 3.14 \\
\hline \# of Voters C & 25 & 9 & 32 & 20 & 14 & 2.89 \\
\hline
\end{tabular}

1. Fuzzy pairwise comparisons by Linguistic are formulated as table 3.

Table 3 Linguistic Importance for Main Dimensions

\begin{tabular}{|c|c|c|c|c|}
\hline Criteria & T & F & C & S \\
\hline T & Equally & A little. H & H & A. Higher \\
\hline F & & Equally & H & M. Higher \\
\hline C & & & Equally & R. Higher \\
\hline S & & & & Equally \\
\hline
\end{tabular}

2. Convert qualitative criterions to quantitative criterions by using membership function as table 4. 
Table 4 Main Dimensions Paired Comparisons

\begin{tabular}{|c|c|c|c|c|}
\hline Criteria & $\mathbf{T}$ & $\mathbf{F}$ & $\mathbf{C}$ & $\mathbf{S}$ \\
\hline $\mathrm{T}$ & $(1,1,1)$ & $(1 / 2,1,3 / 2)$ & $(3 / 2,2,5 / 2)$ & $(5 / 2,3,7 / 2)$ \\
\hline $\mathrm{F}$ & & $(1,1,1)$ & $(3 / 2,2,5 / 2)$ & $(2,5 / 2,3)$ \\
\hline $\mathrm{C}$ & & & $(1,1,1)$ & $(1,3 / 2,2)$ \\
\hline $\mathrm{S}$ & & & & $(1,1,1)$ \\
\hline
\end{tabular}

$\lambda_{\max }=4.006331, \mathrm{CI}=0.00211, \mathrm{CR}=0.004058$

1. Define the fuzzy weights and the best non fuzzy performance for the main criterion, Table 5.

Among the four main and determining dimensions for customer satisfaction Technical Quality dimensions was the most significant one, and Socio-demographic (S) was the least significant one. People answering the question said the lowest position of Sociodemographic (S) was due to Cultural factors. It can also due to the fact that Customer Satisfaction in banking system is almost a new subject and recently some researchers are being done in this regard. Table 5 illustrates the fuzzy weights and the best non fuzzy performance, for the detail calculation see appendix.

Table 5 Main Dimensions weights and BNP

\begin{tabular}{|c|c|c|c|c|}
\hline Criteria & $\mathbf{L}$ & $\mathbf{M}$ & $\mathbf{U}$ & $\mathbf{B N P}$ \\
\hline $\mathrm{T}$ & 0.345729 & 0.347661 & 0.356593 & 0.349994 \\
\hline $\mathrm{F}$ & 0.340704 & 0.351353 & 0.359463 & 0.350507 \\
\hline $\mathrm{C}$ & 0.177355 & 0.178296 & 0.18686 & 0.180837 \\
\hline $\mathrm{S}$ & 0.115521 & 0.116058 & 0.124407 & 0.118662 \\
\hline
\end{tabular}

\section{The criteria of Technical quality $T$}

Technical quality $\mathbf{T}$ contains many sub criteria, Service quality and demand (T1), Service quality perception (T2), The ideal public service (T3), Global quality of services (T4), Reception and welcome (T5), Services area (T6), and Service identification (T7). Table 6 illustrates the fuzzy weights.

Table 6 Summary of 100 questioner for Technical quality (T)

\begin{tabular}{|c|c|c|c|c|c|c|}
\hline \multirow{2}{*}{ Dimension } & \multicolumn{5}{|c|}{ Importance } & \multirow{3}{*}{ Weights } \\
\hline & not & Weak & Important & V. Important & Extremely & \\
\hline Weights & 1 & 2 & 3 & 4 & 5 & \\
\hline \# of Voters T1 & 5 & 15 & 25 & 25 & 30 & 3.6 \\
\hline \# of Voters T2 & 10 & 17 & 23 & 30 & 20 & 3.33 \\
\hline \# of Voters T3 & 15 & 27 & 18 & 25 & 15 & 2.98 \\
\hline \# of Voters T4 & 12 & 7 & 28 & 18 & 35 & 3.57 \\
\hline \# of Voters T5 & 0 & $1 ` 0$ & 45 & 25 & 20 & 3.55 \\
\hline \# of Voters T6 & 10 & 30 & 40 & 15 & 5 & 2.75 \\
\hline \# of Voters T7 & 20 & 30 & 20 & 20 & 10 & 2.7 \\
\hline
\end{tabular}

Fuzzy pair wise comparisons by Linguistic are formulated as table 7. 
Table 7 Linguistic Importance For Technical quality (T)

\begin{tabular}{|c|c|c|c|c|c|c|c|}
\hline $\mathrm{Ti}$ & $\mathrm{T} 1$ & $\mathrm{~T} 2$ & $\mathrm{~T} 3$ & $\mathrm{~T} 4$ & $\mathrm{~T} 5$ & $\mathrm{~T} 6$ & $\mathrm{~T} 7$ \\
\hline $\mathrm{T} 1$ & $\mathrm{E}$ & $\mathrm{H}$ & $\mathrm{V} . \mathrm{H}$ & $\mathrm{M}$ & $\mathrm{R} . \mathrm{H}$ & $\mathrm{V} . \mathrm{H}$ & $\mathrm{A}$ \\
\hline $\mathrm{T} 2$ & $1 / \mathrm{H}$ & $\mathrm{E}$ & $\mathrm{M}$ & $1 / \mathrm{R} . \mathrm{H}$ & $1 / \mathrm{M}$ & $\mathrm{R} . \mathrm{H}$ & $\mathrm{R} . \mathrm{H}$ \\
\hline $\mathrm{T} 3$ & $1 / \mathrm{V} . \mathrm{H}$ & $1 / \mathrm{M}$ & $\mathrm{E}$ & $1 / \mathrm{H}$ & $1 / \mathrm{R} . \mathrm{H}$ & $\mathrm{M}$ & R.H \\
\hline $\mathrm{T} 4$ & $1 / \mathrm{M}$ & $\mathrm{R} . \mathrm{H}$ & $\mathrm{H}$ & $\mathrm{E}$ & $\mathrm{M}$ & $\mathrm{V} . \mathrm{H}$ & $\mathrm{A} . \mathrm{H}$ \\
\hline $\mathrm{T} 5$ & $1 / \mathrm{R} . \mathrm{H}$ & $\mathrm{M}$ & $\mathrm{R} . \mathrm{H}$ & $1 / \mathrm{M}$ & $\mathrm{E}$ & $\mathrm{H}$ & $\mathrm{V} . \mathrm{H}$ \\
\hline $\mathrm{T} 6$ & $1 / \mathrm{V} . \mathrm{H}$ & $1 / \mathrm{R} . \mathrm{H}$ & $1 / \mathrm{M}$ & $1 / \mathrm{V} . \mathrm{H}$ & $1 / \mathrm{H}$ & $\mathrm{E}$ & $\mathrm{M}$ \\
\hline $\mathrm{T} 7$ & 1/A & 1/R.H & 1/R.H & 1/A & $1 / \mathrm{V} . \mathrm{H}$ & $1 / \mathrm{M}$ & $\mathrm{E}$ \\
\hline
\end{tabular}

Table 8 Fuzzy membership functions for Technical quality (T)

\begin{tabular}{|c|c|c|c|c|c|c|c|}
\hline Ti & $\mathbf{T 1}$ & $\mathbf{T 2}$ & $\mathbf{T 3}$ & $\mathbf{T 4}$ & $\mathbf{T 5}$ & $\mathbf{T 6}$ & $\mathbf{T 7}$ \\
\hline T1 & $1,1,1$ & $3 / 2,2,5 / 2$ & $2,5 / 2,3$ & $1 / 2,1,3 / 2$ & $1,3 / 2,2$ & $2,5 / 2,3$ & $5 / 2,3,7 / 2$ \\
\hline T2 & $2 / 5,1 / 2,2 / 3$ & $1,1,1$ & $1 / 2,1,3 / 2$ & $1 / 2,2 / 3,1$ & $2 / 3,1,2$ & $1,3 / 2,2$ & $1,3 / 2,2$ \\
\hline T3 & $1 / 3,2 / 5,1 / 2$ & $2 / 3,1,2$ & $1,1,1$ & $2 / 5,1 / 2,2 / 3$ & $1 / 2,2 / 3,1$ & $1 / 2,1,3 / 2$ & $1,3 / 2,2$ \\
\hline T4 & $2 / 3,1,2$ & $1 / 2,2 / 3,1$ & $3 / 2,2,5 / 2$ & $1,1,1$ & $1 / 2,1,3 / 2$ & $2,5 / 2,3$ & $5 / 2,3,7 / 2$ \\
\hline T5 & $1 / 2,2 / 3,1$ & $1 / 2,1,3 / 2$ & $1,3 / 2,2$ & $2 / 3,1,2$ & $1,1,1$ & $3 / 2,2,5 / 2$ & $2,5 / 2,3$ \\
\hline T6 & $1 / 3,2 / 5,1 / 2$ & $1 / 2,2 / 3,1$ & $2 / 3,1,2$ & $1 / 3,1 / 2,2 / 5$ & $2 / 5,1 / 2,2 / 3$ & $1,1,1$ & $1 / 2,1,3 / 2$ \\
\hline T7 & $2 / 7,2 / 5,1 / 3$ & $1 / 2,2 / 3,1$ & $1 / 2,2 / 3,1$ & $2 / 7,1 / 3,2 / 5$ & $2 / 5,1 / 3,1 / 2$ & $2 / 3,1,2$ & $1,1,1$ \\
\hline
\end{tabular}

$\lambda \max =7.12, \mathrm{CI}=0.02, \mathrm{CR}=0.0148$

Table 9 Technical quality (T) Dimensions Weights and BNP

\begin{tabular}{|c|c|c|c|c|c|}
\hline Ti & L & M & U & BNP & Rank \\
\hline T1 & 0.221654 & 0.239811 & 0.242357 & 0.234607 & 1 \\
\hline T2 & 0.123434 & 0.129421 & 0.136658 & 0.129838 & 4 \\
\hline T3 & 0.105505 & 0.112106 & 0.118305 & 0.111972 & 5 \\
\hline T4 & 0.174187 & 0.187625 & 0.189459 & 0.183757 & 2 \\
\hline T5 & 0.164605 & 0.169709 & 0.174903 & 0.169739 & 3 \\
\hline T6 & 0.089079 & 0.090181 & 0.091588 & 0.090282 & 6 \\
\hline T7 & 0.07614 & 0.076979 & 0.086295 & 0.079805 & 7 \\
\hline
\end{tabular}

The final index for Technical quality (T) indicates to Service quality and demand (T1) is the most preferable to customer satisfaction, where Services area (T7) is the lowest index.

\section{Function Quality criteria}

Function Quality criteria contains sub criteria as professional knowledge F1, Information clarity (F2), Waiting time (F3), Attention and professional interest (F4), and Professional reliability (F5). Table 4.16 Illustrate the fuzzy weights are estimated from the survey and questioner.

Table 10 Summary of 100 Questioner for Functional quality (F)

\begin{tabular}{|c|c|c|c|c|c|c|}
\hline \multirow[b]{2}{*}{ Dimension } & \multicolumn{5}{|c|}{ Importance } & \multirow{3}{*}{ Average } \\
\hline & not & Weak & Important & $\begin{array}{c}V . \\
\text { Important }\end{array}$ & Extremely Important & \\
\hline Weights & 1 & 2 & 3 & 4 & 5 & \\
\hline \# of Voters F1 & 9 & 19 & 20 & 20 & 32 & 3.47 \\
\hline \# of Voters F2 & 26 & 12 & 25 & 17 & 30 & 2.93 \\
\hline \# of Voters F3 & 10 & 5 & 40 & 20 & 25 & 3.45 \\
\hline \# of Voters F4 & 15 & 16 & 32 & 17 & 20 & 3.11 \\
\hline \# of Voters F5 & 10 & 10 & 30 & 27 & 23 & 3.43 \\
\hline
\end{tabular}


Table 11 Linguistic Importance for Function Quality (F)

\begin{tabular}{|c|c|c|c|c|c|}
\hline F & F1 & F2 & F3 & F4 & F5 \\
\hline F1 & E & V.H & M & H & M \\
\hline F2 & $1 / \mathrm{V} . \mathrm{H}$ & $\mathrm{E}$ & $1 / \mathrm{H}$ & $1 / \mathrm{M}$ & $1 / \mathrm{M}$ \\
\hline F3 & $1 / \mathrm{M}$ & $\mathrm{H}$ & $\mathrm{E}$ & R.H & L.H \\
\hline F4 & $1 / \mathrm{H}$ & $\mathrm{M}$ & $1 / \mathrm{RH}$ & $\mathrm{E}$ & L.L \\
\hline F5 & $1 / \mathrm{M}$ & $\mathrm{M}$ & $1 / \mathrm{M}$ & $\mathrm{M}$ & $\mathrm{E}$ \\
\hline
\end{tabular}

Table 12 Fuzzy Pairwise Comparison Matrix for Function Quality(F)

\begin{tabular}{|c|c|c|c|c|c|}
\hline F & F1 & F2 & F3 & F4 & F5 \\
\hline F1 & $(1,1,1)$ & $(2,5 / 2,3)$ & $(1 / 2,1,3 / 2)$ & $(3 / 2,2,5 / 2)$ & $(1 / 2,1,3 / 2)$ \\
\hline F2 & & $(1,1,1)$ & $(2 / 5,1 / 2,2 / 3)$ & $(2 / 3,1,2)$ & $(2 / 3,1,2)$ \\
\hline F3 & & & $(1,1,1)$ & $(1,3 / 2,2)$ & $(1 / 2,1,3 / 2)$ \\
\hline F4 & & & & $(1,1,1)$ & $(2 / 3,1,2)$ \\
\hline F5 & & & & & $(1,1,1)$ \\
\hline
\end{tabular}

Table 13 The Best Non Fuzzy Performance Weights Function Quality (F)

\begin{tabular}{|c|c|c|c|c|c|}
\hline Fi & L & M & U & BNP & Rank \\
\hline F1 & 0.243115884 & 0.261585525 & 0.267753644 & 0.257485 & 1 \\
\hline F2 & 0.140652478 & 0.146336386 & 0.157450488 & 0.148146 & 5 \\
\hline F3 & 0.237455826 & 0.241210082 & 0.241749531 & 0.240138 & 2 \\
\hline F4 & 0.155781951 & 0.15869768 & 0.161206743 & 0.158562 & 4 \\
\hline F5 & 0.178547163 & 0.194062396 & 0.214394224 & 0.195668 & 3 \\
\hline
\end{tabular}

The results indicate that among 5 index technical Function Quality, The final index for Function Quality (F) indicates to the professional knowledge F1 is the most preferable to customer satisfaction and perception are more significant than other indexes, where Information clarity (F2), is the lowest index and the least significant one.

\section{Corporate Image (C) Criteria}

Modernity (C1), the orientation to the customer (C2), and the spreading of the services (C3). Table 14 illustrates Summary of 100 Questioner for Corporate image (C), Table 15 illustrates Linguistic Importance For Corporate Image Dimensions, Table 16 illustrates the Fuzzy Pairwise Comparisons for Corporate Image, Table 17 illustrates the Best Non Fuzzy Performance by Center of Area method. 
Elsayed A. Elsayed

Table 14 Summary of 100 Questioner for Corporate image (C)

\begin{tabular}{|c|c|c|c|c|c|c|}
\hline \multirow{2}{*}{ Dimension } & \multicolumn{5}{|c|}{ Importance } & \multirow{3}{*}{ Average } \\
\hline & not & Weak & Important & V. Important & $\begin{array}{l}\text { Extremely } \\
\text { Important }\end{array}$ & \\
\hline Weights & 1 & 2 & 3 & 4 & 5 & \\
\hline \# of Voters C1 & 5 & 17 & 23 & 15 & 40 & 3.68 \\
\hline \# of Voters C2 & 3 & 20 & 25 & 12 & 40 & 3.66 \\
\hline \# of Voters C3 & 6 & 16 & 29 & 17 & 32 & 3.53 \\
\hline
\end{tabular}

Table 15 Linguistic Importance For Corporate Image Dimensions

\begin{tabular}{|c|c|c|c|}
\hline C & C1 & C2 & C3 \\
\hline C1 & Equally & L.H & R.H \\
\hline C2 & & Equally & L.H \\
\hline C3 & & & Equally \\
\hline
\end{tabular}

Table 16 Fuzzy Pairwise Comparisons for Corporate Image

\begin{tabular}{|c|c|c|c|}
\hline $\mathrm{Ci}$ & $\mathbf{C 1}$ & $\mathbf{C 2}$ & $\mathbf{C 3}$ \\
\hline $\mathrm{C} 1$ & $(1,1,1)$ & $(1 / 2,1,3 / 2)$ & $(1,3 / 2,2)$ \\
\hline $\mathrm{C} 2$ & & $(1,1,1)$ & $(1 / 2,1,3 / 2)$ \\
\hline $\mathrm{C} 3$ & & & $(1,1,1)$ \\
\hline
\end{tabular}

Table 17 The Best Non Fuzzy Performance by Center of Area

\begin{tabular}{|c|c|c|c|c|c|}
\hline Ci & L & M & U & BNP & Rank \\
\hline C1 & 0.347997911 & 0.364012166 & 0.379258606 & 0.363756 & 1 \\
\hline C2 & 0.317993917 & 0.331312909 & 0.347997911 & 0.332435 & 2 \\
\hline C3 & 0.289428485 & 0.304004177 & 0.317993917 & 0.303809 & 3 \\
\hline
\end{tabular}

The results indicate that among 3 index Corporate Image (C) Criteria, The final Corporate Image (C) Criteria indicates to the Modernity is the most preferable to customer satisfaction and then the orientation to the customer $(\mathrm{C} 2)$, where spreading of the services (C3), is the lowest index and the least significant. 


\section{SOCIO-DEMOGRAPHIC DIMENSION}

Socio-Demographic Dimension contains sub-criteria as customer kind (S1), Gender (S2), and Education (S3). Table 18 illustrates Summary of 100 Questioner for Socio-demographic (S), Table 19 illustrates Linguistic Importance for Socio-Demographic Dimension, Table 19 illustrates Fuzzy Pairwise Comparison for Socio-Demographic Dimension, and Table 22 illustrates final weights Socio-Demographic criteria and BNP

Table 18 Summary of 100 Questioner for Socio-demographic (S)

\begin{tabular}{|c|c|c|c|c|c|c|}
\hline \multirow{2}{*}{ Dimension } & \multicolumn{5}{|c|}{ Importance } & \multirow{2}{*}{ Average } \\
\cline { 2 - 6 } & not & Weak & Important & V. Important & Extremely Important & \\
\hline Weights & 1 & 2 & 3 & 4 & 5 & 4 \\
\hline \# of Voters S1 & 5 & 5 & 15 & 35 & 20 & 2.98 \\
\hline \# of Voters S2 & 25 & 9 & 29 & 17 & 50 & 4.2 \\
\hline \# of Voters S3 & 0 & 10 & 10 & 30 & & \multirow{2}{*}{} \\
\hline
\end{tabular}

Table 19 Linguistic Importance for Socio-Demographic Dimension

\begin{tabular}{|c|c|c|c|}
\hline S & S1 & S2 & S3 \\
\hline S1 & $(1,1,1)$ & V. H & L. Lower \\
\hline S2 & V.L & $(1,1,1)$ & A. Lower \\
\hline S3 & L.H & A.H & $(1,1,1)$ \\
\hline
\end{tabular}

Table 20 Fuzzy Pairwise Comparison for Socio-Demographic Dimension

\begin{tabular}{|c|c|c|c|}
\hline $\mathrm{Si}$ & $\mathrm{S} 1$ & $\mathrm{~S} 2$ & $\mathrm{~S} 3$ \\
\hline $\mathrm{S} 1$ & $(1,1,1)$ & $(2,5 / 2,3)$ & $(2 / 3,1,2)$ \\
\hline $\mathrm{S} 2$ & $1 / 3,2 / 5,1 / 2$ & $(1,1,1)$ & $(2 / 7,1 / 3,2 / 5)$ \\
\hline $\mathrm{S} 3$ & $1 / 2,1,3 / 2$ & $5 / 2,3,7 / 2$ & $(1,1,1)$ \\
\hline \multicolumn{3}{|c|}{$\boldsymbol{\lambda} \mathbf{m a x}=\mathbf{3 . 0 0 3 7}, \mathbf{C I}=\mathbf{0 . 0 0 1 8 4 7 ,} \mathbf{C R}=\mathbf{0 . 0 0 3 5 5}$}
\end{tabular}

Table 21 Final Weights Socio-Demographic Dimension

\begin{tabular}{|c|c|c|c|c|c|}
\hline Si & L & M & U & BNP & Rank \\
\hline S1 & 0.409991832 & 0.417775 & 0.438925 & 0.422231 & 1 \\
\hline S2 & 0.141259029 & 0.154327 & 0.173341 & 0.156309 & 3 \\
\hline S3 & 0.408883929 & 0.419816 & 0.435681 & 0.421461 & 2 \\
\hline
\end{tabular}

The Ranking Indexes for Satisfaction Measurement shown in Table 22. 
Elsayed A. Elsayed

Table 22 Ranking Indexes for Satisfaction Measurement

\begin{tabular}{|c|c|c|c|c|c|c|}
\hline Index & $\mathbf{T}$ & $\mathbf{F}$ & $\mathbf{S}$ & $\mathrm{C}$ & Indices Score & $\mathbf{R}$ \\
\hline & 0.349994 & 0.350506548 & 0.180837016 & 0.118662057 & & \\
\hline $\mathrm{T} 1$ & 0.234607 & & & & 0.082111283 & 3 \\
\hline $\mathrm{T} 2$ & 0.129838 & & & & 0.0454424 & 11 \\
\hline T3 & 0.111972 & & & & 0.039189541 & 14 \\
\hline $\mathrm{T} 4$ & 0.183757 & & & & 0.064313991 & 7 \\
\hline T5 & 0.169739 & & & & 0.059407611 & 8 \\
\hline T6 & 0.090282 & & & & 0.031598366 & 16 \\
\hline $\mathrm{T} 7$ & 0.079805 & & & & 0.027931187 & 18 \\
\hline $\mathrm{F} 1$ & & 0.257485018 & & & 0.090250185 & 1 \\
\hline F2 & & 0.148146451 & & & 0.051926301 & 10 \\
\hline F3 & & 0.24013848 & & & 0.084170109 & 2 \\
\hline F4 & & 0.158562124 & & & 0.055577063 & 9 \\
\hline F5 & & 0.195667927 & & & 0.06858289 & 6 \\
\hline S1 & & & 0.422230654 & & 0.076354932 & 4 \\
\hline S2 & & & 0.156308818 & & 0.02826642 & 17 \\
\hline S3 & & & 0.421460528 & & 0.076215665 & 5 \\
\hline $\mathrm{C} 1$ & & & & 0.363756228 & 0.043164062 & 12 \\
\hline $\mathrm{C} 2$ & & & & 0.332434913 & 0.03944741 & 13 \\
\hline $\mathrm{C} 3$ & & & & 0.30380886 & 0.036050584 & 15 \\
\hline
\end{tabular}

The final index and criteria for customer satisfaction illustrates in the Table 23.

Table 23 Ranking Indexes for Satisfaction Measurement

\begin{tabular}{|c|c|c|}
\hline $\mathbf{R}$ & sym & Index \\
\hline 1 & F1 & 0.090250185 \\
\hline 2 & F3 & 0.084170109 \\
\hline 3 & T1 & 0.082111283 \\
\hline 4 & S1 & 0.076354932 \\
\hline 5 & S3 & 0.076215665 \\
\hline 6 & F5 & 0.06858289 \\
\hline 7 & T4 & 0.064313991 \\
\hline 8 & T5 & 0.059407611 \\
\hline 9 & F4 & 0.055577063 \\
\hline 10 & F2 & 0.051926301 \\
\hline 11 & T2 & 0.0454424 \\
\hline 12 & C1 & 0.043164062 \\
\hline 13 & C2 & 0.03944741 \\
\hline 14 & T3 & 0.039189541 \\
\hline 15 & C3 & 0.036050584 \\
\hline 16 & T6 & 0.031598366 \\
\hline 17 & S2 & 0.02826642 \\
\hline 18 & T7 & 0.027931187 \\
\hline
\end{tabular}




\section{CONCLUSION}

A group of investors are participated in the decision-making group to identify evaluation criteria, and to establish evaluation criteria hierarchy. Afterwards, the model captured the judgments of these experts then criteria weights were computed by using AHP-FUZZY based on experts' judgments.

This paper established the complete evaluation guidelines by using qualitative assessments of fuzzy AHP methodology. Our evaluation frame work demonstrates that the Professional knowledge (F1), Waiting time (F3), Service quality and demand (T1), Customer kind (S1), Education (S3) are core criteria in customer satisfaction. As a result, successful banks will use these results in managing, benchmarking and continuously improving measurement methods.

In this paper, the integration of AHP with the fuzzy synthetic extent analysis method (fuzzy AHP) is proposed for customer satisfaction measurement in banking sector as a framework to guide managers. Therefore, fuzzy AHP is an appropriate methodology to select the various types of criteria and has the ability to be used as a decision-making analysis tool. Decision making in practice has shown that fuzzy logic allows decision making with estimated values inspite of incomplete information. It should be noted, however, that a decision may not be correct and can be improved later when additional information is available. Of course, a complete lack of information will not support any decision making using any form of logic. For difficult problems, conventional (non-fuzzy) methods are usually expensive and depend on mathematical approximations (e.g. linearization of nonlinear problems), which may lead to poor performance. Under such circumstances, fuzzy systems often outperform conventional MCDM methods.

\section{REFERENCES}

[1] Adekoya, A., G. et al., "Determining The Strategic Consolidation Of The Capital Base Of Nigerian Commercial Banks Using The Analytic Hierarchy Process (AHP) Model", University of Lagos, Nigeria, 2010.

[2] Ali Görener, "Comparing AHP and ANP: An Application of Strategic Decisions Making in a Manufacturing Company", International Journal of Business and Social Science, Vol. 3 No. 11; June 2012.

[3] Ali Kamil Taslicali, Sami ERCAN, "The Analytic Hierarchy \& the Analytic Network Processes in Multicriteria Decision Making: A comparative study", Journal of Aeronautics and Space Technologies, Volume 2, Number 4, PP.55-65, July 2006.

[4] Chi \& Gorsuy, "Employee satisfaction, customer satisfaction, and financial performance: An empirical examination", International Journal of Hospitality Management, V.28 PP 245:253, 2009.

[5] Chiang Ku Fan, and Shu Wen Cheng, "Using Analytic Hierarchy Process Method and Technique for Order Preference by Similarity to Ideal Solution to Evaluate Curriculum in Department of Risk Management and Insurance", Graduate Institution of Finance and Insurance, Taipei, Taiwan, J Soc Sci, 19(1): 1-8, 2009.

[6] Dejan Cehulic, Tihomir Hunjak, and Nina Begicevic "Comparison of a Bank's Financial Ratios Using the Analytic Hierarchy Process", Faculty of Organization and Informatics, University of Zagreb, Pavlinska 2, 42000 Varazdin, Croatia, 2010.

[7] Fornell, C., "A National Customer Satisfaction Barometer: The Swedish Experience", Journal of Marketing, Vol. 56 No. 1, pp. 6:21, 1992.

[8] G. J. Klir, B. Yuan, Fuzzy sets and fuzzy logic: Theory and application, Prentice Hall, New Jersey, USA, 1995. 
[9] Gupta, M. M., Saridis, G. N., \& Gaines, B. R. "Fuzzy automata and decision processes", New York: Elsevier North-Holland, 1977.

[10] Hansemark, O. C. \& Albinson, M., "Customer Satisfaction and Retention: The Experiences of Individual with Employees”, Managing Service Quality, Vol. 14 (1), 2004.

[11] Hokanson, S., "The Deeper You Analyze The More You Satisfy Customers", Marketing News, January 2, p. 16, 1995.

[12] Hung-Ping Wang, Yao-Min Fang, and Tien-Yin Chou, "MCDM Application on Debris Flow Potential Assessment- CHEN-YU-LAN Watershed", Institute of Environmental and Spatial Information Science and Technology, Feng-Chia University, 2007.

[13] Irfan Syamsuddin , and Junseok Hwang, "The Application of AHP Model to Guide Decision Makers: A Case Study of E-Banking Security", Fourth International Conference on Computer Sciences and Convergence Information Technology, 2009.

[14] L. A. Zadeh, "Fuzzy sets", Information and Control, Vol. 8, 1965, pp.338-353.

[15] Ling $\mathrm{Xu}$, and Jian-Bo Yang "Introduction to Multi-Criteria Decision Making and the Evidential Reasoning Approach", Manchester School of Management University of Manchester Institute of Science and Technology, ISBN: $186115111 \mathrm{X}$, Working Paper No. 0106, May 2001.

[16] M. Bevilacqua, and M. Braglia , "The Analytic Hierarchy Process Applied to Maintenance Strategy Selection", Reliability Engineering and System Safety, 2000, 70(1), pp.71-83, Elsevier Science Ltd., https://doi.org/10.1016/S0951-8320(00)00047-8

[17] Oliver, R. L., Satisfaction: A Behavioral Perspective on the Consumer, New York, McGraw Hill, 1997.

[18] S.A. Nabavi Chashmi et al., "Evaluating \& Ranking the Financial Performance of Bank after Privatization Using AHP FUZZY \& TOPSIS Techniques", Advances in Environmental Biology, 2012, 6(1): pp. 502-508, ISSN 1995-0756.

[19] Salem Yousef Al Wahaidi, "An Analytical Hierarchy Process (AHP) Based Prequalification System for Gaza Strip Construction Contractors", A Thesis Submitted in Partial Fulfillment of the Requirement for the Degree of Master of Science, Civil Engineering, Construction Management, 2012.

[20] Serkan Ball and Serdar Korukoglu, "Operating System Selection Using Fuzzy AHP And TOPSIS Methods", Department of Computer Engineering, Ege University, 35000, Bornova, Izmir, Turkey, Mathematical and Computational Applications, 14(2), pp. 119-130, 2009.

[21] Thomas L. Saaty, "Decision making with the analytic hierarchy process" Int. J. Services Sciences, Vol. 1, No. 1, 2008.

[22] Thomas L. Saaty, "Making and Validating Complex Decisions with the AHP/ANP", Journal of Systems Science and Systems Engineering, Vol. 14, No. 1, pp1-36, March 30, 2005.

[23] Tsaur, S. H., Chang, T. Y., \& Yen, C. H. (2002). The evaluation of airline service quality by fuzzy MCDM. Tourism Management, 23, 107-115.

[24] Tsaur, S. H., Tzeng, G. H., \& Wang, K. C. (1997). Evaluating tourist risks from fuzzy perspectives. Annals of Tourism Research, 24(4), 796-812.

[25] Salem Yousef Al Wahaidi, "An Analytical Hierarchy Process (AHP) Based Prequalification System for Gaza Strip Construction Contractors", A Thesis Submitted in Partial Fulfillment of the Requirement for the Degree of Master of Science, Civil Engineering, Construction Management, 2012. 
[26] Ali GORENER, "Comparing AHP and ANP: An Application of Strategic Decisions Making in a Manufacturing Company", International Journal of Business and Social Science, Vol. 3 No. 11; June 2012.

[27] S.A. Nabavi Chashmi et al., "Evaluating \& Ranking the Financial Performance of Bank after Privatization Using AHP FUZZY \& TOPSIS Techniques", Advances in Environmental Biology, 6(1): 502-508, ISSN 1995-0756, 2012.

[28] Hansemark, O. C. \& Albinson, M.,(2004) "Customer Satisfaction and Retention: The Experiences of Individual with Employees", Managing Service Quality, Vol. 14 (1)

[29] Oliver, R. L., Satisfaction: A Behavioral Perspective on the Consumer, New York, McGraw Hill, 1997.

[30] Hokanson, S., (1995) "The Deeper You Analyze The More You Satisfy Customers", Marketing News, January 2, p. 16.

[31] Fornell, C., (1992). A National Customer Satisfaction Barometer: The Swedish Experience. Journal of Marketing, Vol. 56 No. 1, pp. 6-21

[32] Chi \& Gorsuy, 2009, "Employee satisfaction, customer satisfaction, and financial performance: An empirical examination", International Journal of Hospitality Management V.28 PP 245:253, 2009.

[33] L. A. Zadeh, "Fuzzy sets", Information and Control, Vol. 8, 1965, pp.338-353.

[34] G. J. Klir, B. Yuan, Fuzzy sets and fuzzy logic: Theory and application, Prentice Hall, New Jersey, USA, 1995.

[57] Tsaur, S. H., Tzeng, G. H., \& Wang, K. C. (1997). Evaluating tourist risks from fuzzy perspectives. Annals of Tourism Research, 24(4), 796-812

[36] Tsaur, S. H., Chang, T. Y., \& Yen, C. H. (2002). The evaluation of airline service quality by fuzzy MCDM. Tourism Management, 23, 107-115.

[37] Karsak, E. E. (2002). Distance-based fuzzy MCDM approach for evaluating flexible manufacturing system alternatives. International Journal of Production Research 40(13), 3167-3181.

[38] Zadeh, L. A. (1975). The concept of a linguistic variable and its application to approximate reasoning-I. Information Sciences, 8(3), 199- 249.

[39] Saaty, T. L. (1980). The analytic hierarchy process. New York: McGraw-Hill

[40] Thomas L. Saaty, "How to make a decision: The Analytic Hierarchy Process", European Journal of Operational Research 48 (9-26) 9 North-Holland, 1990.

[41] Evangelos Triantaphyllou, and Stuart H. Mann "Using The Analytic Hierarchy Process For Decision Making In Engineering Applications: Some Challenges", International Journal of Industrial Engineering: Applications and Practice, 2(1), pp. 35-44, 1995.

[42] Jan Jantzen , Tutorial On Fuzzy Logic, Tech University of Denmark, Deptof Automation, Bldg 326, DK-2800 Lyngby, DENMARK. Tech. report no 98-E 868, 19 Aug 1998.

[43] M. Bevilacqua, and M. Braglia , The Analytic Hierarchy Prcc Applied to Maintenance Strategy Sel, Reliability Engg and System Safety (70) 71-83, Elsevier Science Ltd., 2000.

[44] Ling $\mathrm{Xu}$, and Jian-Bo Yang "Introduction to Multi-Criteria Decision Making and the Evidential Reasoning Approach", Manchester School of Management University of Manchester Institute of Science and Technology, ISBN: 186115111 X, Working Paper No. 0106, May 2001.

[45] Thomas L. Saaty, "Making and Validating Complex Decisions with The AHP/ANP", Journal Of Systems Science and Systems Engineering, 14(1), pp1-36, March 30, 2005. 
[46] Ali Kamil TASLICALI, Sami ERCAN, "The Analytic Hierarchy \& The Analytic Network Processes in Multicriteria Decision Making: A comparative study", Journal of Aeronautics and Space Technologies VOLUME 2 NUMBER 4 (55-65), July 2006.

[47] Hung-Ping Wang, Yao-Min Fang, and Tien-Yin Chou, "MCDM Application on Debris Flow Potential Assessment- CHEN-YU-LAN Watershed", Institute of Environmental and Spatial Information Science and Technology, Feng-Chia University, 2007.

[48] Thomas L. Saaty, "Decision making with the analytic hierarchy process" Int. J. Services Sciences, Vol. 1, No. 1, 2008.

[49] Irfan Syamsuddin, and Junseok Hwang, "The Application of AHP Model to Guide Decision Makers: A Case Study of E-Banking Security", Fourth International Conference on Computer Sciences and Convergence Information Technology, 2009.

[50] Chiang $\mathrm{Ku}$ Fan, and Shu Wen Cheng, "Using Analytic Hierarchy Process Method and Technique for Order Preference by Similarity to Ideal Solution to Evaluate Curriculum in Department of Risk Management and Insurance", Graduate Institution of Finance and Insurance, Taipei, Taiwan, J Soc Sci, 19(1): 1-8, 2009.

[51] Serkan Ball and Serdar Korukoğlu, "Operating System Selection Using Fuzzy AHP And TOPSIS Methods", Department of Computer Engineering, Ege University, 35000, Bornova, Izmir, Turkey, Mathematical and Computational Applications, Vol. 14, No. 2, pp. 119-130, 2009.

[52] ADEKOYA, A., G. et al., "Determining The Strategic Consolidation Of The Capital Base Of Nigerian Commercial Banks Using The Analytic Hierarchy Process (Ahp) Model", University of Lagos, Nigeria, 2010. 